Check for updates

The BMJ

aprice@bmj.com

Cite this as: BMJ 2021;373:n1055 http://dx.doi.org/10.1136/bmj.n1055 Published: 28 April 2021

\title{
COMMENTARY
}

\section{Why I wear a mask indoors and out}

\section{Amy Price's husband died from covid-19. She hopes that wearing a mask, outside and indoors, will protect other families from similar trauma}

\section{Amy Price patient editor, The BMJ; senior research scientist, Stanford University School of Medicine}

I became interested in masks professionally when our Stanford laboratory director, Larry Chu, and I did some work about masks for medical professionals and their use in the community. ${ }^{1}$ We then teamed up with the World Health Organization and the Stanford professors Steven Chu and Yi Cui to improve information about masking in the community. ${ }^{2}$

Five nursing friends of my daughter, who is a nurse practitioner working in intensive care, died from covid-19. Simple community mask wearing helped keep my family virus-free until my husband was admitted to hospital with a broken femur. After four weeks of negative covid-19 tests in hospital, he then tested positive and died in hospital from covid-19. He was alone from the ambulance trip until he died. None of us were allowed to visit even once.

\section{Masks reduce droplet spread}

In the hope that it protects other families from similar trauma, I wear a mask in public-indoors and outside-as well as physically distancing, avoiding crowds, and washing my hands regularly.

A face covering does not directly protect wearers from covid-19, because droplets containing the virus can pass through any gaps between the mask and the face. However, modelling suggests that droplets may travel an average of five feet with face covering but 12-30 feet when masks are not worn. ${ }^{3}$ This is why physical distancing matters.

When an infected person is not wearing a mask, the virus can remain for many hours in floating aerosols. ${ }^{3}$ Some people argue that community masks are powerless against aerosols. ${ }^{4}$ Evidence shows, however, that masks prevent most viral particles from escaping. 4

As many as $40 \%$ of people infected with SARS-CoV-2 have no symptoms. ${ }^{5}$ But when we run, talk, cough, or sneeze, respiratory droplets are released into the air. ${ }^{3}$ This is why I wear a mask even outside, wherever people might follow me-for example, in the parking lot, on a city street, or in a queue. Regular mask wearing both inside and outside can help us protect each other by reducing spread at the source, even when we don't know that we're infected.

On the basis of our studies, ${ }^{6}$ the World Health Organization now recommends a cloth mask of at least three layers of different materials. The outermost layer can be a polyester-cotton mix that is slightly water resistant so that droplets won't wick in. The middle layer can be polypropylene or three ply disposable facial tissues. Finally, the innermost layer might be a non-irritating soft cotton to wick moisture away from the face.

The best masks fit snugly but comfortably and cover mid-nose to under the chin and almost to the ears. Moving or talking should not produce gaps or bulges. Breathing and talking should be effort-free. ${ }^{6}$

We found that some materials were as effective as a surgical mask if charged with static electricity ${ }^{6}:$ rub the clean mask with latex gloves or a plastic bag for 30 seconds before use. A similar approach is used in constructing medical protective equipment such as N95 respirators. Overall, charging masks in this way can increase their efficiency by as much as 30\%, and the effect can last for several hours. ${ }^{6}$

\section{Treat it like your toothbrush}

Treat your mask like your toothbrush. Don't share it with anyone, and keep it in a zipped plastic bag when not in use. When you remove it, do so in a way that doesn't spread germs from the front of the mask to your face, and wash your hands after touching the mask. Your mask does not need bleach or harsh chemicals, as these can be breathed into the lungs and cause harm. The mask can be simply laundered with warm water and soap to safely kill SARS-CoV-2.

During the pandemic the World Health Organization, the US Centers for Disease Control and Prevention, and mass media have reported international shortages of personal protective equipment, including masks. If everyone wore a face mask in public, what might it accomplish? Hong Kong and New Zealand employed strong public health support to implement mandatory face masks, indoors and outdoors, and physical distancing. They were more successful than others at reducing viral spread. ${ }^{8}$

Wearing a mask doesn't mean that you are weak or cowardly. It's a way to protect vulnerable people around you. I am vaccinated, yet I wear a mask whether I'm inside or outside, in solidarity with people who are still vulnerable.

Competing interests: I have read and understood BMJ policy on declaration of interests and have no relevant interests to declare.

Provenance and peer review: Commissioned; not externally peer reviewed.

Price A, Chu L. Addressing covid-19 face mask shortages (v 1.3). Learnly Anesthesia, Stanford AIM Lab COVID-19 Evidence Service. Updated 25 Mar 2020. https://stanfordmedicine.app.box.com/v/covid19-PPE-1-2.

2 World Health Organization. Advice on the use of masks in the context of COVID-19: interim guidance, 5 June 2020

(WHO/2019-nCov/IPC_Masks/2020.4). 2020

https://apps.who.int/iris/handle/10665/332293. 
3 Verma S, Dhanak M, Frankenfield J. Visualizing droplet dispersal for face shields and masks with exhalation valves. Phys Fluids (1994) 2020;32:091701. doi: 10.1063/5.0022968.

4 Howard J, Huang A, Li Z, etal. An evidence review of face masks against COVID-19. Proc Natl Acad Sci U S A 2021;118:e2014564118. doi: 10.1073/pnas.2014564118 pmid: 33431650

5 Oran DP, Topol El. Prevalence of asymptomatic SARS-CoV-2 infection: a narrative review. Ann Intern Med 2020;173:362-7. doi: 10.7326/M20-3012 pmid: 32491919

6 Zhao M, Liao L, Xiao W, etal. Household materials selection for homemade cloth face coverings and their filtration efficiency enhancement with triboelectric charging. Nano Lett2020;20:5544-52. https://pubs.acs.org/doi/10.1021/acs.nanolett.0c02211.

doi: 10.1021/acs.nanolett.0c02211 pmid: 32484683

7 Centers for Disease Control and Prevention. How to store and wash masks. Updated $28 \mathrm{Oct}$ 2020. https://www.cdc.gov/coronavirus/2019-ncov/prevent-getting-sick/how-to-wash-clothface-coverings.html.

8 Romero-Severson EO, Hengartner N, Meadors G, Ke R. Change in global transmission rates of COVID-19 through May 6 2020. PLoS One 2020;15:e0236776.

doi: 10.1371/journal.pone.0236776. pmid: 32760158

This article is made freely available for use in accordance with BMI's website terms and conditions for the duration of the covid-19 pandemic or until otherwise determined by BMJ. You may use, download and print the article for any lawful, non-commercial purpose (including text and data mining) provided that all copyright notices and trade marks are retained. 